\title{
HARTWIG, Wolfgang, BRANDT, Harm-Hinrich, Deutschlands Weg in die Moderne. Politik, Gesellschaft und Kultur im 19. Jahrhundert
}

Isabelle von Bueltzingsloewen

\section{(2) OpenEdition}

Édition électronique

URL : http://journals.openedition.org/ifha/1958

DOI : $10.4000 /$ ifha. 1958

ISSN : 2198-8943

\section{Éditeur}

IFRA - Institut franco-allemand (sciences historiques et sociales)

\section{Référence électronique}

Isabelle von Bueltzingsloewen, « HARTWIG, Wolfgang, BRANDT, Harm-Hinrich, Deutschlands Weg in die Moderne. Politik, Gesellschaft und Kultur im 19. Jahrhundert », Revue de I'IFHA [En ligne], Date de recension, mis en ligne le 01 janvier 1995, consulté le 22 septembre 2020. URL : http:// journals.openedition.org/ifha/1958; DOI : https://doi.org/10.4000/ifha.1958

Ce document a été généré automatiquement le 22 septembre 2020.

(CIFHA 


\title{
HARTWIG, Wolfgang, BRANDT, Harm-Hinrich, Deutschlands Weg in die Moderne. Politik, Gesellschaft und Kultur im 19. Jahrhundert
}

\author{
Isabelle von Bueltzingsloewen
}

1 Les dix-neuf contributions rassemblées dans ce recueil constituent des mélanges en l'honneur de Thomas Nipperdey, disparu en juin 1992; ils devaient en principe lui être remis quelques mois plus tard, à l'occasion de son soixante-cinquième anniversaire.

Cette entreprise, qui a mobilisé des historiens de grande notoriété et venus de tous les horizons, témoigne du respect qu'ont toujours suscité les travaux de l'historien de Munich dans l'ensemble de la communauté historienne allemande et internationale.

En hommage à leur collègue et à sa formidable synthèse en trois tomes de l'histoire de l'Allemagne au XIXe s., W.H. et H.-H.B. souhaitaient voir approfondir des thèmes, aussi variés soient-ils, qui avaient particulièrement retenu l'attention de T. Nipperdey tout au long de sa carrière et qui procédaient d'une question centrale, celle de la spécificité de l'entrée de l'Allemagne dans la modernité au cours du XIXe s. Tel est par conséquent le fil directeur, peut-être trop ténu, de cet ouvrage qui regroupe des contributions qui peuvent apparaître bien disparates; on trouvera ainsi deux articles qui portent sur la bourgeoisie (J. KOCKA et H.-H. BRANDT), deux autres qui traitent du rapport des juifs au nationalisme (S. VOLKOV et G.L. MOSSE), deux autres encore consacrés aux universités (H. LÜBBE et E. SHILS), enfin un ensemble plus important de cinq articles traitant du fait culturel et artistique (J.J. SHEEHAN, M. STÜRMER, C.E. SCHORSKE, L. GALL et W.J. MOMMSEN). Ces approches thématiques sont complétées par deux contributions plus générales qui proposent une réflexion sur les modalités de l'évolution historique allemande (W. HARTWIG et F. STERN) et par six autres (P. GAY, S. FISCH, K.H. METZ, E. NOLTE, T. RENDTORFF, F. TENBRUCK) qui s'interrogent sur des notions aussi variées que celle de culture, de démocratisme, d'Unkirchlichkeit ou encore sur la façon dont une société découvre la nouveauté et y répond. Après la 
lecture de ces essais, pour la plupart très stimulants, on ne pourra que regretter l'absence d'une conclusion qui vienne faire la synthèse d'une démarche quelque peu décousue.

4 Isabelle von BUELTZINGSLOEWEN 